\title{
КАЧЕСТВО ЖИЗНИ ДЕТЕЙ И ОСОБЕННОСТИ РОДИТЕЛЬСТВА В УСЛОВИЯХ ПЛЮРАЛИЗАЦИИ ФОРМ СЕМЬИ
}

\author{
Людмила СЛЮСАР ${ }^{\odot}$, кандидат экономических наук, вед. н. с.,
} Институт демографии и социальных исследований имени М.В. Птухи, Национальная академия наук Украины

DOI: https://doi.org/10.36004/nier.cdr.2019.14-14 JEL Classification: J112, J113.

Современная трансформация института семьи, разнообразие структуры, форм и типов семейных объединений, влияют на выполнение семьей ее основных функиий содержание и воспитание детей. Распространение однородительских, реструктурированных, транснациональных семей меняет условия выполнения родительских функиий и условия жизни детей. Автор исследует проблемы и риски, которые возникают в результате этих перемен. Он утверждает, что, с одной стороны, эти изменения являются вызовом для современного общества, так как трансформируют традиционную семейную среду воспитания ребенка, но с другой стороны, они имманентны современному социальнодемографическому развитию, дают новые возможности и позволяют решить ряд демографических проблем. Минимизировать возникающие риски возможно путем модернизации родительских практик согласно принципов "ответственного родительства» и гендерного равенства, т.е. при уважительном, ответственном, педагогически грамотном отночении к ребенку, независимо от формы брачных отношений родителей.

Ключевые слова: семья, родительство, дети, общество, ответственное родительство.

The modern transformation of the institution of the family, the diversity of the structure, forms and types of family associations, influence the fulfillment of basic family functions - the maintenance and socialization of children. The spread of family with single parent, restructured, transnational families is changing the conditions for fulfilling parental functions and the living conditions of children. The author explores the problems and risks arising as result of these changes. He argues that, on the one hand, these changes are challenge for modern society, since they change the traditional family environment for life of a child, but on the other hand, they are immanent to modern socio-demographic development, provide new opportunities and allow solving some demographic problems. It is possible to minimize these risks by modernizing parental practices on the principles of responsible parenthood and gender equality, i.e. with a respectful, responsible, pedagogically competent attitude to the child, regardless of the form of the marriage relationship of the parents.

Key words: family, parenthood, children, society, responsible parenthood.

В современном мире, в начале XXI века, когда человечество находится на новом этапе своего развития и постиндустриальные принципы социальной и технологической организации распространяются все в большем количестве стран, происходят кардинальные системные изменения во всех сферах социума, в том числе в демографической сфере. Значительны достижения в повышении продолжительности жизни и снижении смертности, растущая мобильность населения сочетается в развитых странах с небывалым снижением рождаемости, а также сложными и противоречивыми изменениями института семьи. Современная трансформация формы, функций, структуры семейных объединений, обусловленная как новыми потребностями социального и экономического развития, так и

\footnotetext{
๑ Людмила Слюсар 1.slyusar@bigmir.net
} 
изменениями в демографических процессах, влияет на жизнь всех поколений, всех возрастных групп, в т. ч. на качество жизни детей.

Многообразие типов, размера, структуры семейных объединений всегда формирует определенные различия в условиях развития ребенка, особенности в системе отношений родители-дети. Определенные различия в выполнении функций содержания и воспитания детей (основных демографических функций семьи) имеют городские и сельские семьи, многодетные и однодетные семьи, простые и сложные (многопоколенной) семьи, семьи, в которых родители имеют разный уровень образования, социальный и профессиональный статус, уровень доходов и т.п. Однако при всех этих различиях, если дети в семье живут с отцом и матерью, т.е. с обоими биологическими родителями, то они воспитываются в традиционной семейной среде и форма родительства традиционна.

В настоящее время получили распространение семьи, в которых выполнение родительских функций качественно изменено: однородительские семьи, реструктурированные семьи, семьи с дистанционным браком. Форма родительства и соответственно условия жизни ребенка в этих семьях трансформированы: родительские функции выполняет только один из родителей или неродной отец / мать, или осуществляется «родительство на расстоянии». Такие семьи всегда имели место, однако в прошлом возникали в результате действия внешних негативных факторов (войн, эпидемий, насилия, природных катаклизмов). Сейчас появление таких семей в большинстве случаев обусловлено современными особенностями брачно-семейного поведения: нестабильностью брака, распространением внебрачной рождаемости, миграционной мобильностью лиц разного брачного статуса. Это изменило и восприятие таких семей, сделали их типичными, «полноправными» среди семей с детьми. По данным обследования "Fertility and family surveys in countries of the ECE region", хотя во всех развитых странах в большинстве случаев ребенок живет в семье с двумя биологическими родителями, однородительские и реструктурированные семьи (чаще всего родная мать и отчим) стали обычным явлением во всех странах региона. Место однородительских и реструктурированных семей на жизненном пути ребенка в различных странах удачно демонстрируют расчеты P. Heuveline, J.M. Timberlake, F.F. Furstenberg Jr. по данным этого обследования [3]: жизнь ребенка до 15 лет распределяется по среднему количеству лет, прожитых в различных типах родительских семей - Рис. 1. Этот рисунок наглядно демонстрирует, что на момент обследования однородительские семьи значительно влияли на жизнь детей в Германии, США, Австрии, Канаде, Латвии, Швеции, реструктурированные - в США, Чехии, Латвии, Австрии.

Качество жизни ребенка, условия воспитания и взаимодействия с родителями в этой категории семей принципиально изменены, поэтому существуют много критических оценок выполнения ними родительских функций. Вместе с тем исследователи, изучающие условия жизни детей в семье, приходят к разным выводам. Так, Elizabeth Thomson и Sara McLanahan на основе своего лонгитюдного исследования качества жизни детей в семьях разных типов пришли к выводу о его негативных изменениях во всех «альтернативных» формах семьи: незарегистрированный брак биологических родителей, не родной отец, однородительская семья. Особенно неблагоприятны, по их мнению, условия жизни детей в семьях, где их воспитывает мать и отчим, брак которых официально не зарегистрирован [5]. Вместе с тем, ряд исследователей доказывают, что однородительские и реструктурированные семьи имеют достаточный потенциал для полноценного воспитания и развития ребенка. Такого мнения придерживается 3. Матейчек [7, с. 70-98]. Т. А. Гурко, на основании проведенных в 1994 и 2010-2011 годах выборочных обследований, делает вывод об отсутствии значительных различий в развитии, поведении и жизненных планах подростков из полных и неполных (однородительских) семей [6, с. 81-90]. 


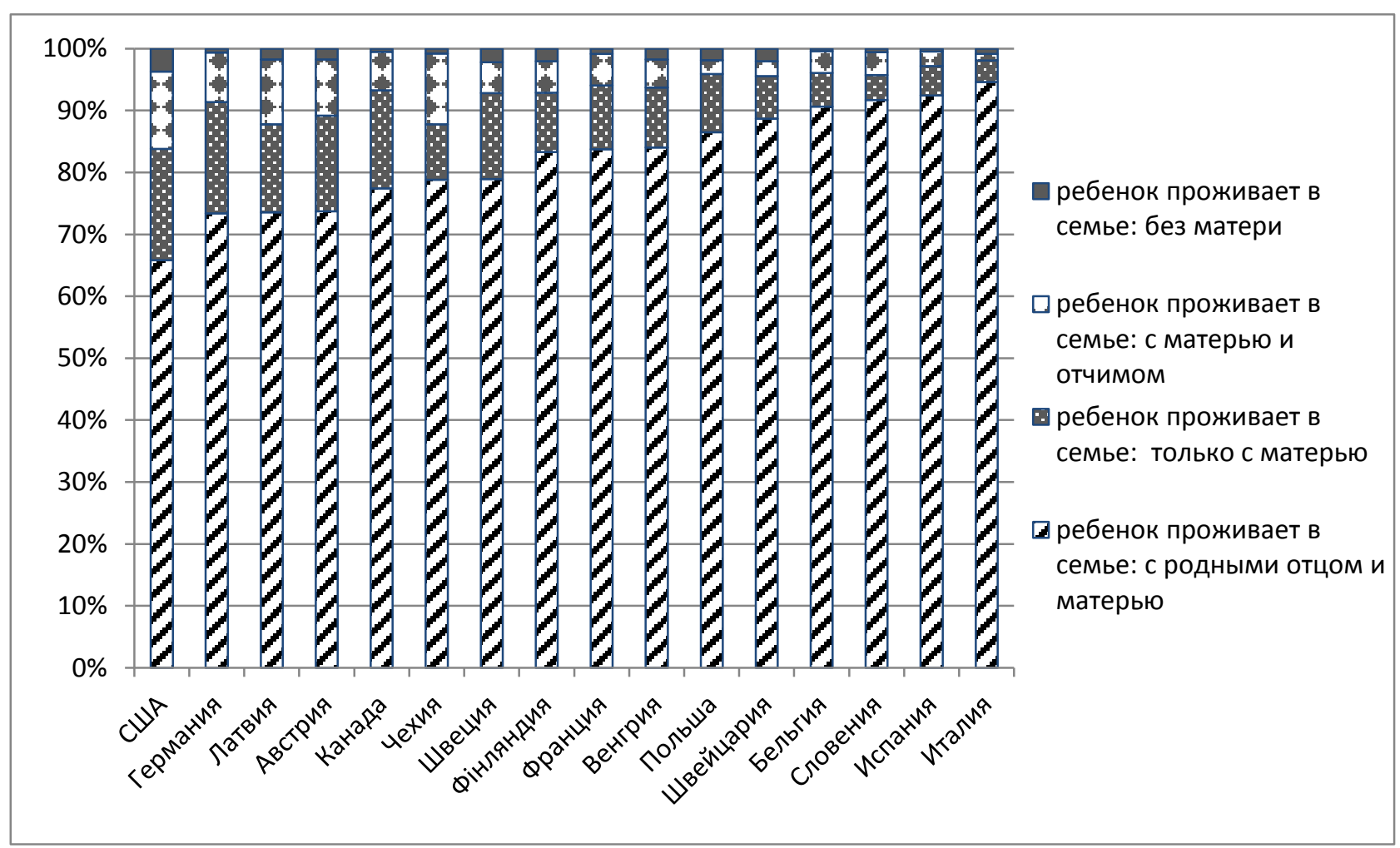

Рисунок 1. Ожидаемая продолжительность жизни детей в разных типах семей

(в годах, от рождения до 15 лет)

Источник: Рассчитано по Heuveline P., Timberlake J.M. and Furstenberg Jr. F.F. Shifting childrearing to single mothers: results from 17 western countries [3]

Следует признать, что рост количества семей, в которых форма родительства трансформирована из-за особенностей структуры семьи (однородительские, реструктурированные, транснациональные семьи), является определенным вызовом для современного общества, поскольку наиболее комфортной для ребенка является семья, где его содержат и воспитывают родные отец и мать. Условия реализации функций родительства в подобных семьях существенно отличаются от традиционных, что порождает определенные проблемы и риски.

Анализируя качество жизни детей в однородительских семьях, традиционно в первую очередь обращают внимание на экономические проблемы. Даже в Швеции, которая известна активной политикой поддержки семей с детьми, сравнять экономические условия жизни детей в неполных и полных семьях удалось не полностью. В экономически слабых странах, к которым относится Украина, где низкий уровень доходов большинства населения, однородительские семьи особенно экономически уязвимыми, значительная их часть находится ниже черты бедности. По данным ежегодных выборочных обследований условий жизни домохозяйств Украины, денежные расходы домохозяйств, в составе которых есть дети, не имеющие одного из родителей, ниже, чем в остальных домохозяйствах с детьми, большая часть средств расходуется на питание, а рацион питания хуже [1, с.110-112, 285290]. Уровень субъективной бедности среди украинских семей с детьми высок, но особенно - среди семей, в которых дети не имеют одного из родителей: чаще относят себя к бедным, постоянно отказывают себе в самом необходимом, не могут обеспечить даже достаточное питание. Среди этих семей наиболее тяжелое положение там, где воспитывается трое и больше детей (Таблица 1.).

Кроме экономических проблем, которые в экономически благополучном обществе могут быть минимизированы, существуют многочисленные психологические и 
педагогические риски, возникающие в результате изменений традиционной среды воспитания и жизнедеятельности ребенка. Многие исследования указывают на риск депрессии и асоциального поведения детей; из-за отсутствия одного из родителей ребенку трудно полноценно формировать гендерные стереотипы поведения, понять особенности взаимодействия в семье лиц разного пола. Мать, которая сама воспитывает ребенка, часто сталкивается со сложностью отношений с ребенком, не может контролировать его поведение. Проблемы всех однородительских семей, независимо от причины их образования, общие, однако есть и определенная специфика: если один из родителей умер или погиб, положительные воспоминания о нем могут поддержать доброжелательную атмосферу в семье, смягчать проблемы в воспитании ребенка; если родители развелись, важна степень их дальнейшего участия в жизни общих детей. Украина относится к странам, где отсутствует традиция участия отца в воспитании детей после распада брака, и часто нет понимания необходимости такого участия со стороны матери.

Таблица 1. Распределение домохозяйств с детьми по самооценке уровня их доходов, \% (Украина, 2019)

\begin{tabular}{|c|c|c|c|}
\hline & $\begin{array}{c}\text { все } \\
\text { домохозяйства } \\
\text { с детьми }\end{array}$ & $\begin{array}{c}\text { домохозяйства, } \\
\text { в которых дети } \\
\text { не имеют одного } \\
\text { или обоих } \\
\text { родителей } \\
\end{array}$ & $\begin{array}{c}\text { среди них те, } \\
\text { где трое и } \\
\text { больше детей }\end{array}$ \\
\hline \multicolumn{4}{|c|}{$\begin{array}{c}\text { Распределение домохозяйств по самооценке уровня их доходов } \\
\text { на протяжении последнего года: }\end{array}$} \\
\hline $\begin{array}{l}\text { было достаточно и делали } \\
\text { сбережения }\end{array}$ & 8,4 & 6,9 & 12,7 \\
\hline $\begin{array}{l}\text { было достаточно, но } \\
\text { сбережений не делали }\end{array}$ & 55,3 & 44,2 & 17,1 \\
\hline $\begin{array}{l}\text { постоянно отказывали себе в } \\
\text { самом необходимом, кроме } \\
\text { питания }\end{array}$ & 33,3 & 43,3 & 32,9 \\
\hline $\begin{array}{l}\text { не удавалось обеспечить даже } \\
\text { достаточное питание }\end{array}$ & 3,0 & 5,6 & 37,3 \\
\hline \multicolumn{4}{|c|}{$\begin{array}{c}\text { Распределение домохозяйств, которые за оценкой своего материального положения } \\
\text { относят себя: }\end{array}$} \\
\hline к обеспеченным (богатым) & - & - & - \\
\hline $\begin{array}{l}\text { к представителям среднего } \\
\text { класса }\end{array}$ & 1,3 & 1,2 & - \\
\hline $\begin{array}{l}\text { к небедным, но еще не к } \\
\text { представителям среднего класса }\end{array}$ & 33,7 & 23,0 & 1,7 \\
\hline к бедным & 65,0 & 76,8 & 98,3 \\
\hline
\end{tabular}

Источник: Самооцінка домогосподарствами України рівня своїх доходів (за даними вибіркового опитування домогосподарств у січні 2019 року). Статистичний збірник. - К.: Держстат України, 2019, с. 21-30

Если в однородительских семьях на первом плане проблемы с экономическим обеспечением содержания детей, то в реструктурированных - проблемы в отношениях детей с супругом (супругой) матери (отца), которые должны заменить им родных родителей, что довольно сложно. В этих семьях существует риск психологического, эмоционального напряжения, недопонимания между ребенком и отчимом/мачехой, возможны конфликты. Чешские исследователи, изучая психологический и эмоциональное состояние детей разного пола в однородительских и реструктурированных семьях, пришли к выводу, что проживание в семье без отца негативно влияет прежде всего на мальчиков, которые требуют 
определенного «отстранения» от матери, чтобы сформировать свою мужскую идентичность, a в реструктурированных семьях психологический дисбаланс испытывают особенно девушки, которым трудно с отчимом [4].

Однородительские и реструктурированные семьи продуцируют определенные риски, в тоже время их создание является способом разрешения ряда социально-демографических проблем. Однородительская семья формируется как результат разрешения кризисной ситуации: неудачный брак, кризис в супружеских отношениях (который достаточно часто проявляется в резких, в том числе асоциальных, формах), невозможность для женщины найти постоянного брачного партнера. Проживание ребенка в условиях кризиса супружеских отношений родителей имеет много рисков, негативно влияет на его развитие, психологическое и эмоциональное состояние, и «выход» ребенка из этой ситуации путем развода родителей часто нельзя оценивать отрицательно. Рождение ребенка одинокой (незамужней) женщиной, если ребенок желанный и решение ответственное, для общества является положительным событием. Реструктурированные семьи способны улучшить материальные условия жизни ребенка, дать ощущение защищенности. «полноты» семейного окружения. Хотя возможны эмоциональные проблемы во взаимоотношениях ребенка и отчима/мачехи, при доброжелательном, грамотном подходе они преодолимы. К примеру, согласно данным украинского социологического исследования «Здоровье и поведенческие ориентации ученической молодежи», половина опрошенных, у которых неродной отец или мать, сообщили, что им «легко» или «очень легко» говорить с ними на важные темы (Таблица 2.). И хотя с родными родителями подростки общаются на эти темы значительно чаще, следует отметить, что половина реструктурированных семей также смогли сформировать доверительные отношения [2, с. 33].

Таблица 2. Доля респондентов 11-17 лет, ответивших «легко» и «очень легко» на вопрос: «Насколько легко тебе говорить на темы, которые тебя по настоящему

волнуют, с такими людьми...», \%

\begin{tabular}{|l|c|c|c|}
\hline & парни & девушки & все опрошенные \\
\hline с отцом & 81,6 & 71,3 & 76,7 \\
\hline с неродным отцом & 55,5 & 51,3 & 53,5 \\
\hline с матерью & 88,1 & 88,4 & 88,3 \\
\hline с неродной матерью & 49,7 & 43,5 & 47,0 \\
\hline
\end{tabular}

Источник: [2, с. 33]

Неоднозначна ситуация и в транснациональных семьях, рост числа которых является результатом интенсификации миграционных процессов. Если в такой семье есть ребенок, он или живет с одним из родителей, или, если за границей работает мать, которая сама воспитывает ребенка, ребенок находится на попечении родственников. Соответственно, форма родительства в такой семье существенно изменена, родительские функции «выполняются дистанционно». Внешняя трудовая миграция позволяет повысить благосостояние семьи, получить средства на содержание детей, их образование, смягчает проблемы безработицы и низкой оплаты труда. По данным опроса, проведенного в 2017 г. социологической группой «Рейтинг», одним из главных мотивов работы за рубежом украинцев было желание заработать на жилье, обучение детей, лечение родственников; а одной из причин, побудивших думать об эмиграции, - «желание обеспечить лучшее будущее для детей». Улучшая материальные условия жизни детей, транснациональные семьи ухудшают условия их социализации, деформируя выполнение родительских обязанностей; и, хотя современные средства связи создают возможности для частого общения, «воспитание на расстоянии» не является полноценным, родители часто отдаляются от реальных проблем своих детей. 
Современные формы брака и семьи соответствуют исторической логике демографического развития, современному типу воспроизводства населения. Вместе с тем, существует определенное противоречие между современной формой брачных отношений (отход от модели брака на всю жизнь, плюрализация форм брака) и потребностью общества в комфортных условиях социализации подрастающего поколения, которые обеспечивает традиционный институт родительства. Семья, в которой ребенка содержат и воспитывают родные отец и мать, является наиболее комфортной для ребенка, естественная привязанность детей и родителей минимизирует многие риски, обеспечивает защищенность развития, усвоения норм и правил гендерного взаимодействия в семье. Разрешение этого противоречия требует не возврата к старым формам брачно-семейного поведения, а модернизации института родительства на современных принципах понимания ценности каждого ребенка, ответственного, грамотного отношения к родительским обязанностям вне зависимости от формы формальных и неформальных отношений отца и матери. Это новое качество родительства получило название «ответственное родительство». Современное ответственное родительство основывается на гармоничном сочетании родительских функций и самореализации личности в других сферах деятельности, характеризуется сознательным, грамотным отношением к рождению ребенка и к его воспитанию, партнерскими отношениями между родителями и между родителями и детьми, гибким подходом к гендерным ролям в семье. Трансформация гендерных ролей в современной семье приводит к появлению модели «нового отца», чьи обязанности не сводятся к кормильцу семьи, он активно вовлечен в организацию быта ребенка и его воспитание.

Достижения современной медицины расширили группу семей, в которых родительство «выходит за биологические границы», то есть не связано с кровнородственными отношениями. Если ранее это были лишь семьи, усыновившие ребенка (традиционная форма устройства детей, которых не могут воспитывать биологические родители из-за их гибели, отсутствие и т.п.), то теперь ребенок может родиться с использованием донорства половых клеток или суррогатного материнства. Новые репродуктивные технологии «отделили» биологическое и социальное родительство, что значительно расширило возможности для рождения желаемого количества детей, однако искусственная фрагментация процесса деторождения стала причиной ряда социальных, этических и юридических проблем и рисков.

Bbыюды. В результате современной трансформации института семьи, модернизации брачно-семейного поведения населения, получили распространение семьи, в которых условия жизни ребенка значительно изменены: однородительские, реструктурированные, транснациональные семьи. Эти семьи имеют свою специфику выполнения родительских функций, экономические и педагогические проблемы, специфические риски по сравнению с традиционной семьей. В экономически слабых странах, к которым относится Украина, эти проблемы стоят особенно остро. Однако если в семье создана доброжелательная, гармоничная атмосфера, если ребенок воспитывается согласно принципам «ответственного родительства» (уважительное, ответственное, педагогически грамотное отношение), такие семьи могут качественно и в полной мере выполнять функции по содержанию и воспитанию ребенка. Все же эта группа семей требует внимания со стороны общества: поддержки путем разработки и распространения рекомендаций педагогов, психологов, а при необходимости и материальной помощи. 


\section{Библиография}

1. Витрати і ресурси домогосподарств України у 2018 році. Статистичний збірник. К.: Державна служба статистики України, 2019, 379 с.

2. Соціальна обумовленість та показники здоров'я підлітків та молоді (за результатами соціологічного опитування в межах міжнародного проекту «Здоров’я та поведінкові орієнтації учнівської молоді». К.: Поліграфічний центр «Фоліант», 2019, 127 с.

3. Heuveline P., Timberlake J.M. and Furstenberg Jr. F.F. Shifting childrearing to single mothers: results from 17 western countries. Population and Development Review, 2003, 29(1), p. 47-71. DOI: 10.1111/j.1728-4457.2003.00047.x

4. Petr Bob et al. Dissociative Symptoms and Mother's Marital Status in a Young Adult Population. Medicine 94.2, 2015: e408, Web. WCF Natural Family News and Research. http://mbox.bigmir.net/read/INBOX/56be3dcc9fb8/?p=5\& rand=1617339240.

5. Thomson Elizabeth and McLanahan Sara S. Reflections on 'Family Structure and Child Well-Being: Economic Resources vs. Parental Socialization. Social Forces 91.1, 2012, p. 45-53. http://sf.oxfordjournals.org/content/91/1/45 (extract).

6. Гурко Т.А. Особенности развития личности подростков в различных типах семей. Социологические исследования, 1996, № 3, с. 81-90.

7. Матейчек 3. Некоторые психологические проблемы воспитания детей в неполной семье. Воспитание детей в неполной семье. Общ. ред. Н. М. Ершовой. М.: Прогресс, 1980, с. 70-98. 